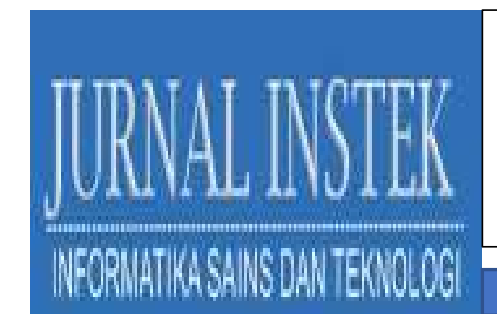

Volume 6 Nomor. 1, April 2021

P-ISSN : 2541-1179, E-ISSN : 2581-1711

Ojs :http://journal.uin-alauddin.ac.id/index.php/instek/index

Email : instek@uin-alauddin.ac.id

\title{
EKSPLORASI WEB BROWSER DALAM PENCARIAN BUKTI DIGITAL MENGGUNAKAN SQLITE
}

\author{
HARIANI ${ }^{1}$ \\ Teknik Informatika, Fakultas Sains dan Teknologi, Universitas Islam Negeri \\ Alauddin Makassar ${ }^{1}$ \\ Email: hariani.kasim@uin-alauddin.ac.id ${ }^{1}$
}

\begin{abstract}
ABSTRAK
Penggunaan Internet yang meningkat membuat semakin maraknya pengguna web browser. Hal ini bisa memberikan dampak pada meningkatnya kejahatan dunia maya menggunakan media tersebut misalnya menyebarkan hoax, penipuan Email dan lain-lain. Penelitian ini bertujuan untuk mengetahui pentingnya melihat aktivitas pada web browser baik terhadap korban maupun pelaku. Hal ini bisa menentukan pola kejahatan pada suatu kasus dan membantu penyidik dalam menganalisis bukti digital yang tersimpan pada WEB Browser sehingga kasus bisa di selesaikan dengan baik dan tepat. Penelitian ini menunjukkan lokasi history pencarian pada cookie, cache, history download dan melihat password yang tersimpan di web browser safari, maxthon dan comodo dragon menggunakan SQLite. Hasil analisis menunjukkan bahwa banyak Informasi yang di peroleh dari bukti digital web browser menggunakan SQLite sehingga metode ini dapat di terapkan untuk mendapatkan bukti digital jika di perlukan sebagai pembuktian sebuah kasus.
\end{abstract}

Kata kunci - Web Browser, SQLite, Bukti Digital

\section{PENDAHULUAN}

Perkembangan teknologi membuat penggunaan Internet semakin pesat, Kebutuhan Informasi dan Ilmu pengetahuan berperan dalam perkembangannya. Penggunaan Internet di Indonesian terus bertambah setiap harinya, Kategori pengguna internet juga beragam, berdasarkan kelompok usia pada tahun 2017. usia 13-18 tahun sekitar (16.68\%), 19-34 tahun sekitar (49.52\%), 35-54 sekitar $(29,55 \%),>54$ tahun sekitar (4.24\%) Presentase ini tersebar di usia 19-34 yaitu sebesar $49.52 \%$, usia tersebut termasuk ke dalam usia produktif / generasi muda. 


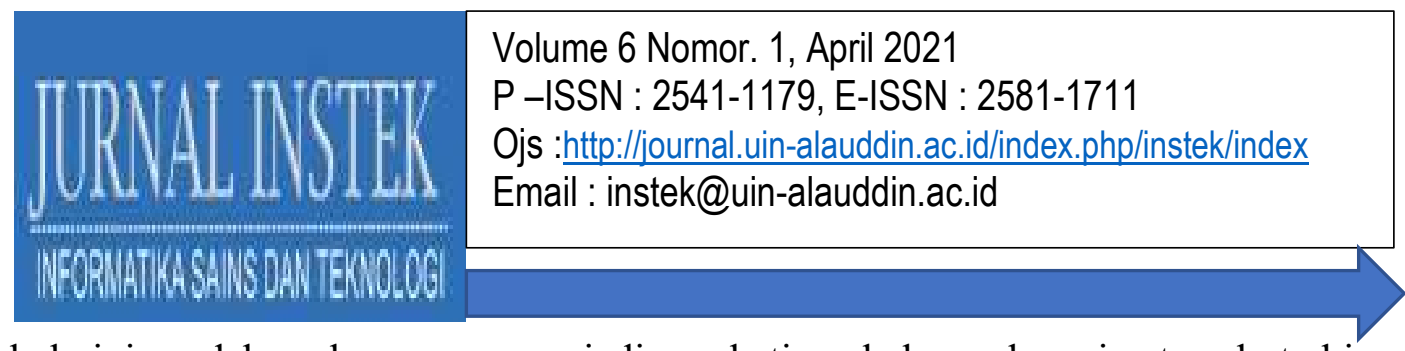

hal ini sudah seharusnya menjadi perhatian kelompok usia tersebut bisa memaksimalkan manfaat internet dengan baik (Said 2018).

Pada perkembangannya Internet tidak hanya membawa dampak positif tapi juga membawa dampak negative, Internet dapat membuat kejahatan yang bersifat konvensional berkembang menjadi kejahatan melalui teknologi dengan tingkat kerugian yang besar dan meluas atau disebut dengan istilah cybercrime (Dista, 2011).

Web Browser merupakan aplikasi atau software yang digunakan untuk melakukan pencarian atau menjelajahi Internet guna memperoleh Informasi dari suatu web. Pada awalnya, browser hanya dapat menampilkan teks, namun pada perkembangannya web browser kini tidak hanya menampilkan teks saja, tetapi juga dapat mendukung pemutaran multimedia seperti video dan suara ( wisnu 2020). Selain itu, web browser juga dapat mengirim dan menerima E-mail, mengelola HTML sebagai input pencarian dan menampilkan kembali halaman web sebagai output yang Informatif (Daniel, Rendra, Rizka, Rory, Wayan 2014). hampir setiap hari kita menggunakan web browser untuk menjelajah Internet dengan beragam pencarian sesuai kebutuhan, bahkan kejahatan dunia maya banyak terjadi dengan penggunaan web browser (Sidiq, Fiaz 2019).

Web browser dapat menyimpan aktifitas browsing dari pengguna berupa informasi URL yang dikunjungi, file dan gambar yang di unduh, cookie, cache dan Informasi lainnya (Said, Mutawa, Awadhi \& Guimaraes 2011). Pengguna yang mempunyai kepedulian terhadap privasi browsing maka mereka ingin web browser tidak meninggalkan jejak Informasi history pencarian selama mereka berselancar di Internet (Satvat, Forshaw, Hao \& Toreini, 2014). Namun, bagi penyidik hal tersebut sangat penting jika itu terkait dengan sebuah kasus.

\section{METODE PENELITIAN}

Beberapa penelitian sebelumnya yang telah di lakukan mengenai bukti digital pada web browser antara lain penelitian yang dilakukan oleh Varol dan Sonmez bahwa setiap aktivitas pada web adalah data yang dapat mengungkap pikiran dan niat pengguna seperti kata pencarian, kunjungan web, file yang diunduh. Penelitian 


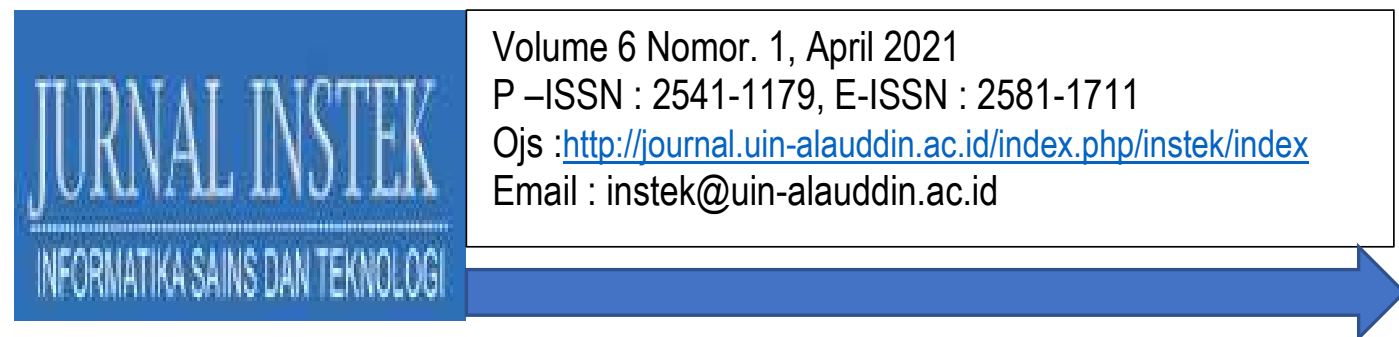

ini menghasilkan model atau metode baru untuk meningkatkan proses digital forensics. Analisis aktivitas web browser harus diperiksa secara rinci. Jika metode atau model kesuksesan ini dijalankan maka membutuhkan mesin pencari data untuk komputer forensics.

Penelitian berikutnya oleh Runa dengan melakukan analysis forensic pada Tor Browser, hasilnya ditemukan jejak yang berhubungan langsung dengan Tor Browser Bundle pada OS X, Linux dan Windows, Sebagian besar masalah yang ditemukan menunjukkan jejak paket Bundel Tor Browser pada sistem penggunanya.

Selanjutnya penelitian di lakukan oleh Sidiq dan Faiz mengenai web browser, dimana penelitiannya memberikan penjelasan lokasi penyimpanan bukti digital, format waktu yang digunakan dan 10 tools yang digunakan penyidik dalam mengungkap kejahatan dengan media web browser seperti Google Chrome, Mozilla Firefox, Internet Explorer, Safari dan Opera.

Penelitian kali ini bersifat eksplorasi menggunakan beberapa tahap yaitu Simulasi, Pencarian Lokasi Database dan Analisis. Pada penelitian ini dibatasi menggunakan 3 jenis web browser yaitu Safari, Maxthon dan Comodo Dragon dengan melakukan analisis pada lokasi penyimpanan data pada browser tersebut seperti Cache, Cookies, History URL, download dan Save Password untuk mencari bukti digital yang di butuhkan. Berikut Langkah-langkah yang di lakukan:

\section{Simulasi aktifitas pada Web Browser}

Penelitian ini menggunakan simulasi pada web browser, misalnya melakukan pencarian, membuka email dan memasukkan password. Aktifitas yang dilakukan pada browser akan tersimpan dan terekam di database web browser. Informasi inilah yang dapat di ambil dan di lakukan analisis untuk mencari informasi bukti digital yang di butuhkan. Aktifitas ini tersimpan di cache, Cookies, History URL, Download dan Save Password. 


\section{Mencari Lokasi Database}

Tahap kedua yaitu mencari posisi file yang akan di analisis, karena perbedaan Sistem Operasi yang digunakan juga akan mempengaruhi posisi file-file tersebut.

Tabel 1. Contoh lokasi File pada Safari

\begin{tabular}{|c|c|}
\hline Browser & Path \\
\hline Cache & C/:user/En2/AppData/Local/AppleComputer/Safari/Cache \\
\hline \multirow[t]{2}{*}{ Cookies } & C: \Users\En2\AppData\Roaming \Apple \\
\hline & Computer $\backslash$ Safari $\backslash$ Cookies \\
\hline \multirow[t]{2}{*}{ History } & C: \Users \En2\AppData\Roaming \Apple \\
\hline & Computer $\backslash$ Safari $\backslash$ History. \\
\hline
\end{tabular}

\section{Analisis Fitur Menggunakan SQLite}

Tahap selajutnya yaitu agar bisa melihat Informasi pada aktiftas yang terekam di dalam database Web Browser kita menggunakan bantuan tools untuk menganalisis, pada penelitian ini di gunakan SQLlite. Tools ini merupakan aplikasi untuk membuat, mencari dan mengedit sebuah database.

\section{HASIL DAN PEMBAHASAN}

\section{A. Hasil Analisis}

\section{Safari Browser}

Web browser yang pertama kita analisis adalah Safari. Banyak yang menggunakan Safari dalam melakukan pencarian karena tampilannya yang berbeda dengan browser lainnya, elemen desainnya canggih sehingga browsing jadi menyenangkan. Hasil analisis dari beberapa path yang di peroleh seperti cache yang posisinya terletak di C/:user/En2/AppData/Local/AppleComputer/Safari/Cache berisi beberapa table jika dilihat dengan menggunakan open database SQLiteSpy yaitu, cache blob data, cache receiver, cache respons, cache schema dan sqlite sequence. Berikut tampilannya. 

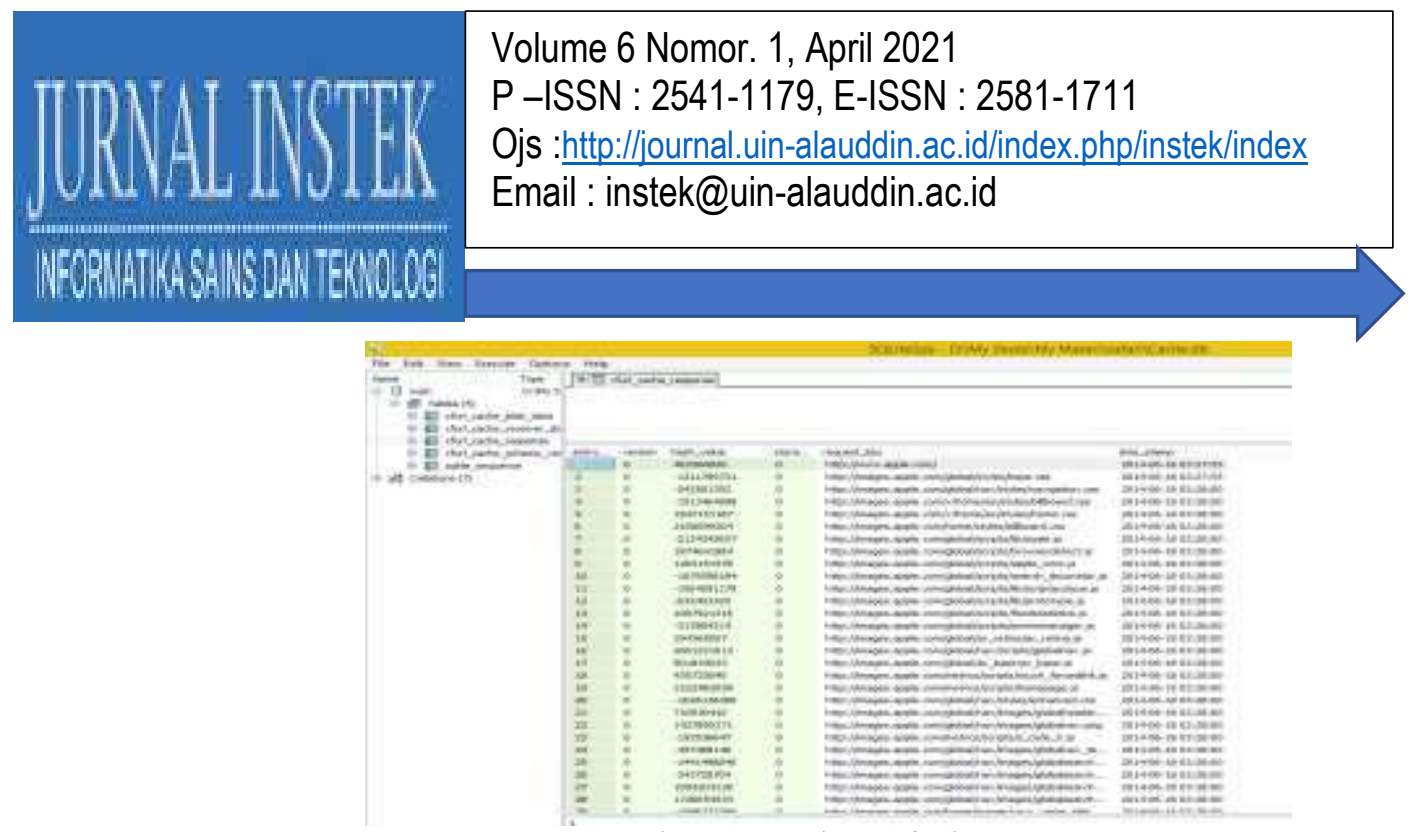

Gambar 1. cache safari

Selanjutnya Cookies yang terletak di C:IUsers \En2 \AppData \Roaming $\backslash$ AppleComputer $\backslash$ Safari\Cookies. Analisis Cookies pada safari tidak bisa dilakukan menggunakan SQLiteSpy karena database tersebut terenkripsi sehingga informasi yang di dapatkan pada bagian ini jadi terbatas. File berikutnya adalah History. File ini terletak di $\mathrm{C}: \backslash U$ sers $\backslash E n 2 \backslash A p p D a t a \backslash$ Roaming $\backslash A$ pple Computer $\backslash$ Safari $\backslash$ History. analisa melalui menggunakan SQLiteSpy juga tidak bisa dilakukan, namun dapat dilihat melalui web browser safari seperti gambar dibawah.

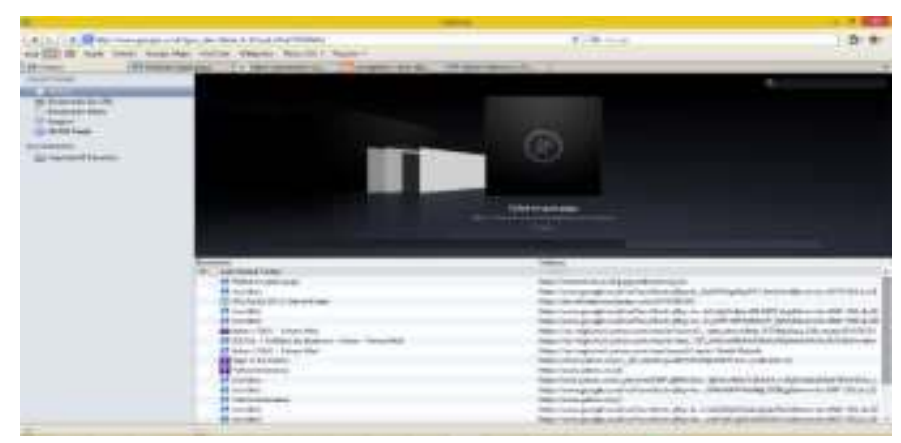

Analisis pada History Download sama dengan History diatas, bisa ditampilkan melalui web browser safari. Untuk Saved Password apabila pengguna login ke suatu situs yang menggunakan password, maka secara otomatis password akan tersave pada browser tersebut. Namun pada safari untuk loader password menggunakan tools tersendiri yang disebut Safari Password Decryptor, dengan aplikasi ini akun dan password dari user bisa terlihat. Seperti terlihat pada gambar berikut. 

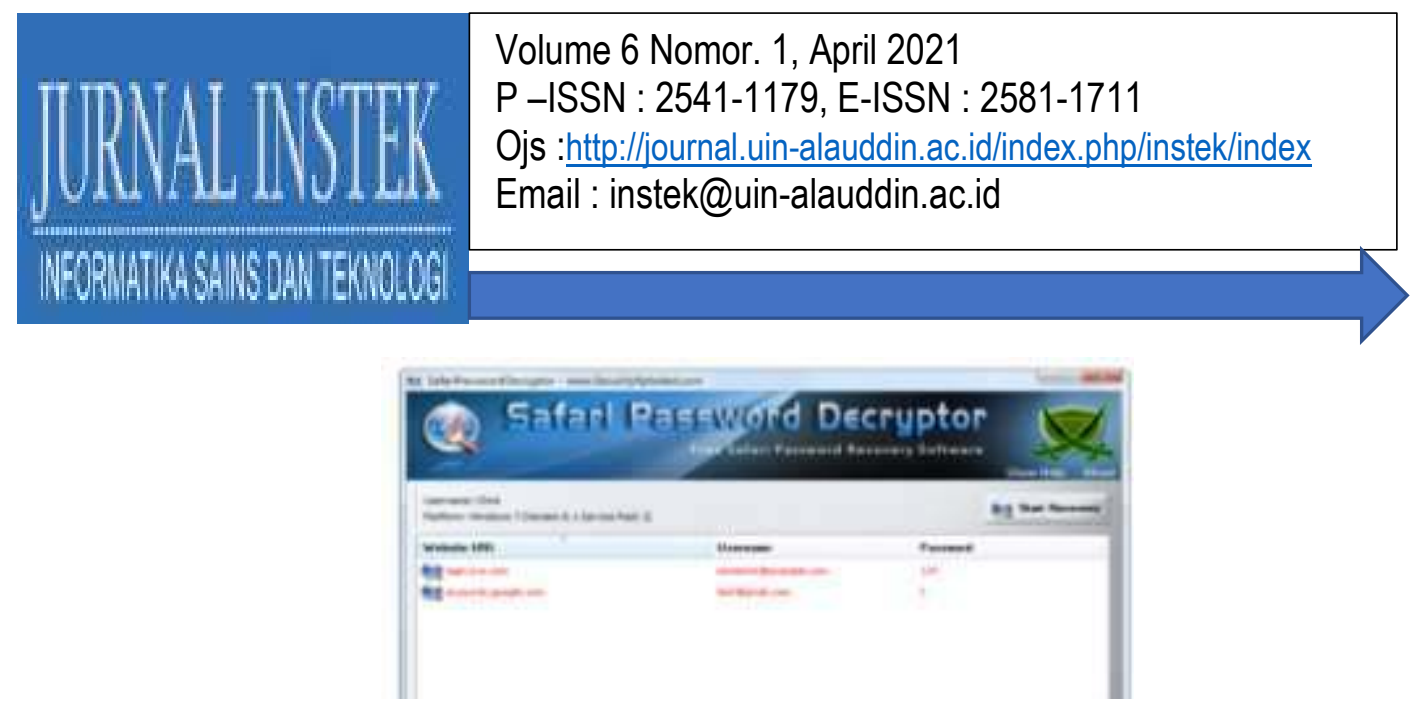

Gambar 3. save password

\section{Maxthon Browser}

Analisis selanjutnya yaitu Maxthon Browser. Database Cache terletak di C: \Users\En2\AppData\Roaming \Maxthon3 \users\guestlcaches. Cache maxthon juga tidak bisa dianalisa menggunakan SQLliteSpy karena file terenkripsi. Selanjutnya Cookie yang terletak di C: $\backslash$ Users $\backslash$ En2 $\backslash$ AppData $\backslash$ Roaming $\backslash$ Maxthon3 lusers Iguest $\backslash$ Cookielcookie.dat. cookie ini berisi key pencarian pada browser, seperti terlihat pada gambar.

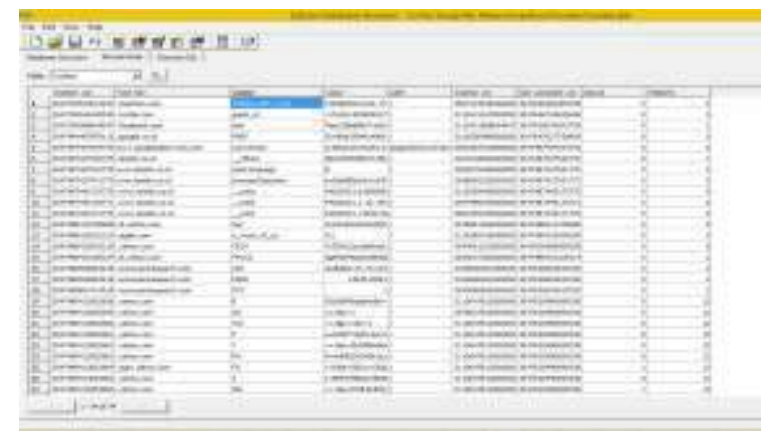

Gambar 4. Cookie

Database History pada Maxthon tidak bisa dianalisa menggunakan SQLlite karena file terenkripsi, namun history dapat dilihat melalui web Maxthon. Untuk Saved Password Informasi pada database tersebut juga terenskripsi, namun bisa dilihat melalui web browsernya. 


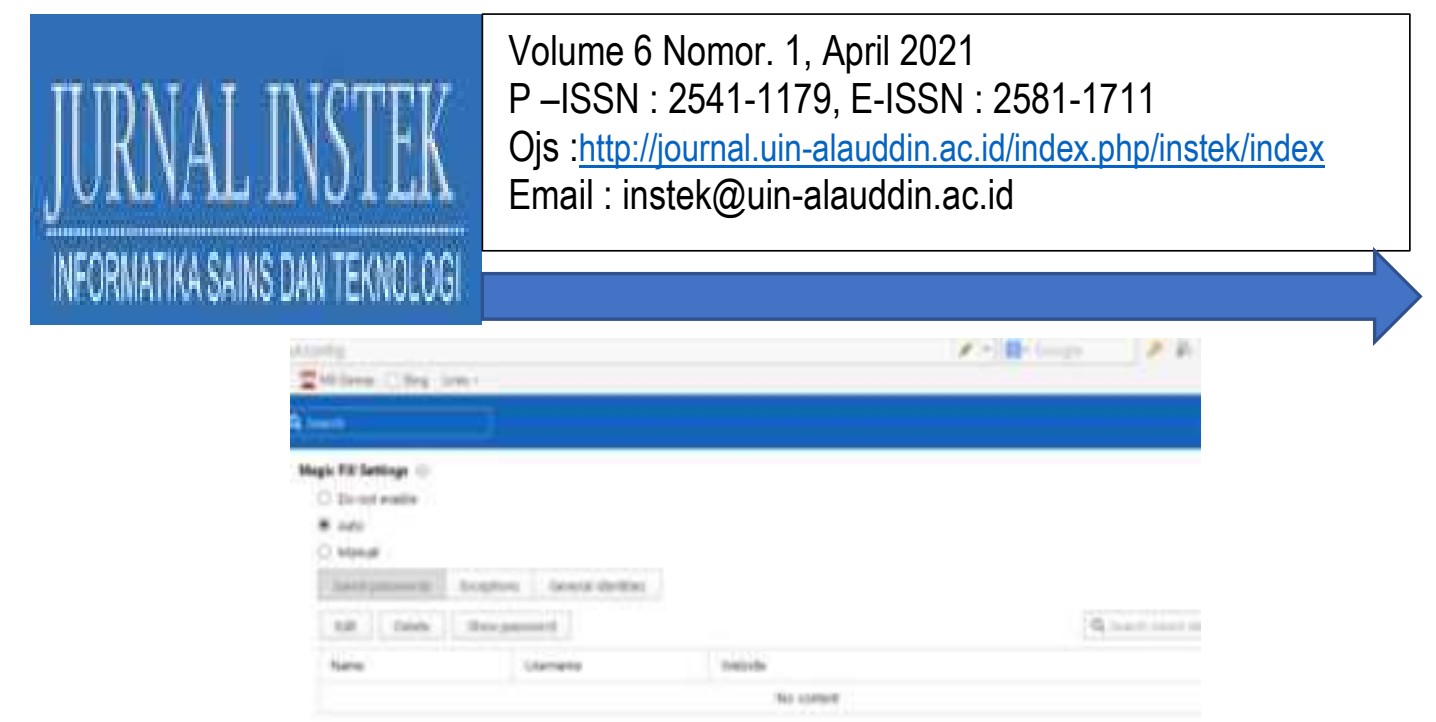

Gambar 5. password browser

\section{Comodo Dragon Browser}

Cache pada Comodo Dragon berisi file dat dan tidak bisa dianalisa dengan SQLliteSpy atau file tersebut terenkripsi. untuk Cookies yang terletak di $\mathrm{C}$ :

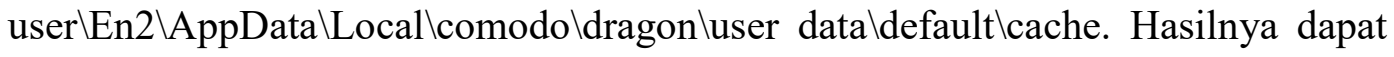
dilihat berupa informasi dari pencarian yang dilakukan oleh user.

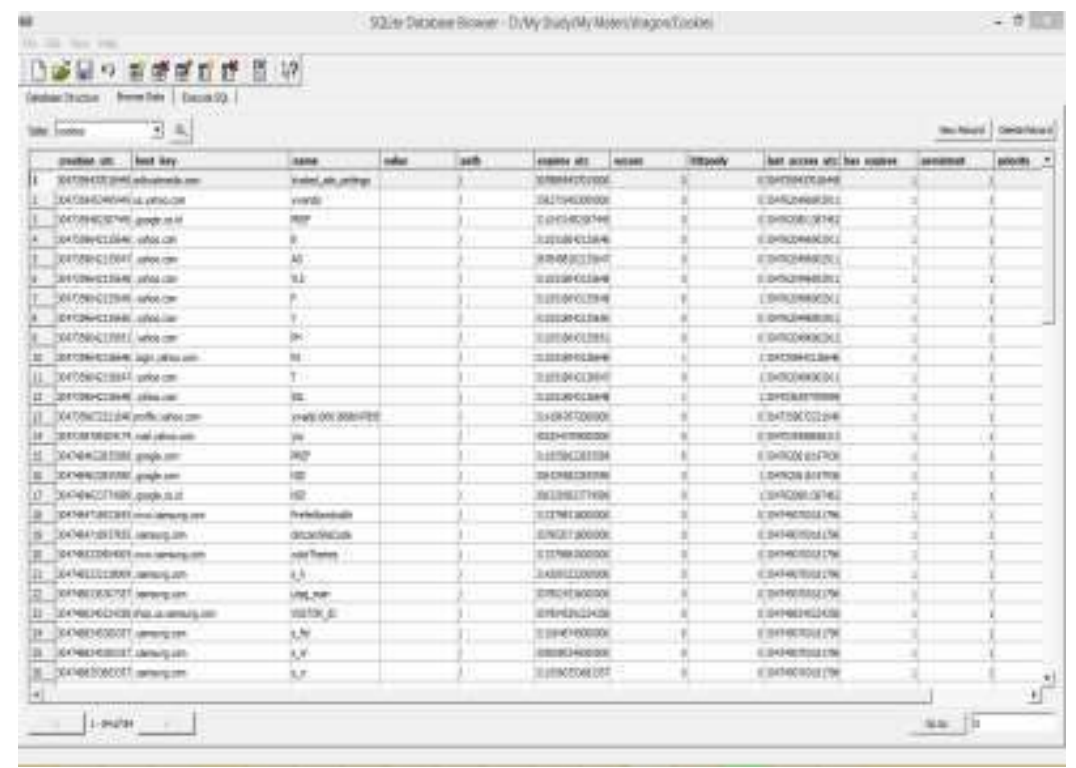

Gambar 6. Informasi cookie

Analisis History dengan menggunakan SQliteSpy dapat dilihat informasi URL yang di cari oleh user pada saat browsing. History ini terletak di $\mathrm{C} \backslash$ : user $\backslash E n 2 \backslash A p p D a t a \backslash L o c a l \backslash c o m o d o \backslash d r a g o n \backslash u s e r$ dataldefault thistory.untuk History Download mempunyai satu database dengan History URL, sedangkan hasil analisis Saved Password yang berlokasi di Cl: user $\backslash$ En2 \AppData 


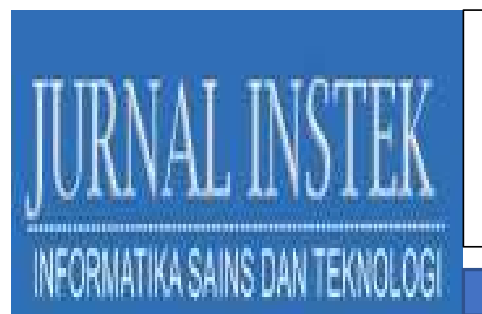

Volume 6 Nomor. 1, April 2021

P-ISSN : 2541-1179, E-ISSN : 2581-1711

Ojs :http://journal.uin-alauddin.ac.id/index.php/instek/index

Email : instek@uin-alauddin.ac.id

\Local\comodoldragon $\backslash$ user dataldefault $\backslash$ login dapat di lihat. Cara yang lain untuk melihat saved password bisa langsung melalui web browser Comodo.

\section{B. Komparasi Hasil Analisis}

Hasil analisis dari Browser diatas dapat di lihat dari tabel komparasi berikut.

Tabel 2. Komparasi Hasil Analisis

\begin{tabular}{|c|c|c|c|c|c|}
\hline \multirow{2}{*}{$\begin{array}{c}\text { WEB } \\
\text { Browser }\end{array}$} & \multicolumn{5}{|c|}{ Komparasi Hasil Analisis } \\
\hline & Cache & Cookies & $\begin{array}{c}\text { History } \\
\text { WEB }\end{array}$ & Download & $\begin{array}{c}\text { Saved } \\
\text { Password }\end{array}$ \\
\hline Safari & $\begin{array}{l}\text { Tools } \\
\text { SQLite: } \\
\text { Bisa } \\
\text { dianalisa }\end{array}$ & $\begin{array}{l}\text { Tools } \\
\text { SQLite: } \\
\text { terenkripsi. }\end{array}$ & $\begin{array}{l}\text { Tools } \\
\text { SQLite: } \\
\text { terenkripsi, } \\
\text { namun bisa } \\
\text { dianalisa } \\
\text { melalui web } \\
\text { browser. }\end{array}$ & $\begin{array}{l}\text { Analisa } \\
\text { melalui } \\
\text { web } \\
\text { browser. }\end{array}$ & $\begin{array}{l}\text { Dianalisa } \\
\text { menggunakan } \\
\text { tools Safari } \\
\text { Password } \\
\text { Decryptor. }\end{array}$ \\
\hline Maxthon & $\begin{array}{l}\text { Tools } \\
\text { SQLite: } \\
\text { terenkripsi }\end{array}$ & $\begin{array}{l}\text { Tools } \\
\text { SQLite: } \\
\text { Bisa } \\
\text { dianalisa }\end{array}$ & $\begin{array}{l}\text { Tools } \\
\text { SQLite: } \\
\text { Terenkripsi } \\
\text { tapi bisa } \\
\text { dianalisa } \\
\text { melalui web } \\
\text { browser. }\end{array}$ & $\begin{array}{l}\text { Analisa } \\
\text { melalui } \\
\text { web } \\
\text { browser. }\end{array}$ & $\begin{array}{l}\text { Tools } \\
\text { SQLite: } \\
\text { terenkripsi } \\
\text { namun bisa } \\
\text { dianalisa } \\
\text { melalui web } \\
\text { browser. }\end{array}$ \\
\hline $\begin{array}{l}\text { Comodo } \\
\text { Dragon }\end{array}$ & $\begin{array}{l}\text { Tools } \\
\text { SQLite: } \\
\text { terenkripsi. }\end{array}$ & $\begin{array}{l}\text { Tools } \\
\text { SQLite: } \\
\text { bisa } \\
\text { dianalisa. }\end{array}$ & $\begin{array}{l}\text { Tools } \\
\text { SQLite: } \\
\text { bisa } \\
\text { dianalisa. }\end{array}$ & $\begin{array}{l}\text { Tools } \\
\text { SQlite: bisa } \\
\text { dianalisa. }\end{array}$ & $\begin{array}{l}\text { Tools } \\
\text { SQLite: bisa } \\
\text { dianalisa. }\end{array}$ \\
\hline
\end{tabular}

\section{KESIMPULAN}

Web browser forensics menjadi salah satu proses penting dalam proses investigasi digital forensics. Web browser mempunyai peranan penting pada kejahatan yang terjadi karena di gunakan untuk mengakses guna melancarkan aksi pelaku. Penyidik sebaiknya mengetahui bahwa web browser dapat menyimpan data, menyimpan riwayat kata-kata pencarian, URL yang pernah dikunjungi, riwayat unduhan dan lainnya. Informasi ini berguna dan dijadikan sebagai bukti digital yang bisa mengungkapkan suatu kejahatan. Sebab itu, penyidik harus melakukan nalisis data web browser dengan teliti. 
Volume 6 Nomor. 1, April 2021

P-ISSN : 2541-1179, E-ISSN : 2581-1711

Ojs :http://journal.uin-alauddin.ac.id/index.php/instek/index

Email : instek@uin-alauddin.ac.id

Penelitian ini menjelaskan Informasi apa saja yang dapat di dapatkan pada database web browser dengan menggunakan SQLite hasilnya sangat membantu dalam pencarian bukti digital meskipun ada beberapa Informasi database tidak sepenuhnya bisa di dapatkan, tapi dengan kombinasi tools lainnya Informasi tersebut bisa didapatkan. misalnya menggunakan Password Dekriptor untuk membuka Database yang terenkripsi.

\section{DAFTAR PUSTAKA}

A. Varol and Y. U. Sonmez, -The Importance of Web Activities for Computer Forensics, $\|$ in 2017 International Conference on Computer Science and Engineering (UBMK), 2017, no. December, pp. 1-7

Cholish H., Makhsun, T. 2017. Analisa Forensik Memori Volatil data Browser Pada Layanan Internet Banking. Jurnal Teknologi Informasi ESIT Vol. IX (2)

Daniel S, Rendra S, Rizka K, Rory, I wayan S.W. 2014. Membandingkan Kinerja Web Browser. Repository Gunadarma

Dita, A.R. 2011. Kasus Cybercrime Di Indonesia: UNISSULA Vol. 18 No. 2: 185 195

Muhammad, F.S., Muhammad, N.F. 2019. Review Tools Web Browser Forensics untuk Mendukung Pencarian Bukti Digital. Jurnal Edukasi dan Penelitian Informatika. Vol.5(1)

Noorulla, E. S. (2014). Web Browser Private Mode Forensics Analysis.

Rochmadi, T. 2017. Analisis Anti Forensik pada Portable Web Browser Mode Private Menggunakan Metode Live Forensik.

Sandvik, R. A. (2013). Forensic Analysis of the Tor Browser Bundle on OS X, Linux, and Windows, 1-13.

Wisnu, S. 2020. Metode Offline Forensic Untuk Analisis Digital Artefak Pada TOR Browser di Sistem Operasi Linux 